\title{
Stress Analysis in Cam Using Analytical, FEM \& Photo elasticity Techniques
}

\author{
Manoj Baseshankar ${ }^{1,}$ Manjeet Gajbhiye ${ }^{2}$, Nitin Kumbhare ${ }^{3}$ \\ ${ }^{1,2,3}$ Assistant Professor \\ Department of Mechanical Engineering, Suryodaya College of Engineering \& Technology
}

Received on: 11 December, 2020, Revised on: 11 January, 2021, Published on: 16 January, 2021

\begin{abstract}
A cam is a versatile, specially shaped part of a machine that is always in contact with a member is called the follower. The most important task before design engineer is to maintain the working stresses within predetermined specific limits, in order to avoid the failure of a member. In the present work, the stress analysis is carried out on a snail cam by analytical, FEM and photo elastic (experimental) techniques and results are put in the comparative manner.
\end{abstract}

Keywords - Cam, Photoelasticity, FEM.

\section{I- INTRODUCTION}

C am design is constantly evolving. New techniques and information are available for cam synthesis, analysis, dynamics, and performance and the production of the actual cam body itself. The cam profile accuracy is of utmost importance in any cam and follower application. A surface appearing to be smooth may have poor dynamic properties. Depending on the application and loads the cam profile accuracy and its surface finish may affect the life, vibration, and noise of a camfollower system.

As the name implies, stress analysis is the complete and comprehensive study of stress distribution of specimen under study. A good design engineer always strives to maintain the working stresses on any machine component within predetermined specific limits. To improve the product quality it is necessary to determine the stresses in various components. It is also necessary to know the stress distribution in order to predict the failure of component. Therefore it is of paramount importance to carry stress analysis as a part of a good design.

The stress analysis can be done by following techniques: Numerical, Experimental and Analytical. In the present work, a snail type cam was stress analyzed by all the three techniques mentioned above.

\section{II-LITERATURE REVIEW}

Pástor, M. et.al.,used both classical experimental technique of photo elasticity as well as modern one digital image correlation by stress analysis methods to compare the corresponding stress fields obtained on a sample with stress concentrators loaded by bending [1]. Heather Driscolla et.al., designed an experimental set-up to capture the dynamic maximum shear stress fringes occurring when a studded outsole came into contact with the photo elastic surface. Image processing methods were used to clearly identify the fringes [2]. Hawong $\mathrm{J}$. S. et.al., worked on the use of black and white isochromatic in photo elastic experimental hybrid method and found that the black and white isochromatic requires high fringe orders in order to obtain sufficient experimental data for photo elastic hybrid techniques [3]. Prasanth Kumar et.al., found that the major stresses induced in the bell crank lever at the fulcrum are bending stress and fulcrum pin is shear stress and the maximum stresses are developed at the fulcrum. They 


\section{International Journal of Innovations in Engineering and Science, www.ijies.net}

found that the experimental and analytical results are in close agreement with each other [4].

\section{III-STRESS ANALYSIS BY ANALYTICAL METHOD}

In analytical method the radial and circumferential stresses are calculated using the following data and relations.

Inner radius, $r_{1}=0.0125 \mathrm{~m}$

Outer radius, $r_{2}=0.04 \mathrm{~m}$

$\mathrm{N}=45$ r.p.m

$\omega=4.71 \mathrm{rad} / \mathrm{sec}$

$\mu=0.29$

$\rho=7500 \mathrm{~kg} / \mathrm{m}^{3}$

$\sigma_{\mathrm{c}}=\frac{\rho \times \omega^{2}}{8}(3+\mu)\left[\left(\mathrm{r}_{2}^{2}+\mathrm{r}_{1}^{2}\right)+\frac{\mathrm{r}_{1}^{2} \mathrm{r}_{2}^{2}}{\mathrm{r}^{2}}-\frac{\mathrm{r}^{2}(1+3 \mu)}{(3+\mu)}\right]$

............Circumferential Stress

$\sigma_{\mathrm{r}}=\frac{\rho \times \omega^{2}}{8}(3+\mu)\left[\left(\mathrm{r}_{2}^{2}+\mathrm{r}_{1}^{2}\right)+\frac{\mathrm{r}_{1}^{2} \mathrm{r}_{2}^{2}}{\mathrm{r}^{2}}-\mathrm{r}^{2}\right]$

..................Radial Stress

By substituting the different values of $r$ in the above equation, different values of $\sigma_{\mathrm{r}}$ are obtained. Also $\sigma_{\mathrm{r}}=0$ at $r=0.0125 \mathrm{~m}$ and at $r=0.04 \mathrm{~m}$. Also we have got in problem that $\sigma_{\mathrm{r}}$ is maximum at $r=\sqrt{r_{1} r_{2}}=$ $\sqrt{0.0125 \times 0.04}=0.02236 \mathrm{~m}$. Let us start the calculations from inner radius $(=0.0125 \mathrm{~m})$. The circumferential and radial stresses, calculated at diffèrent radii by analytical method are given in table 1 , The variation of $\sigma_{\mathrm{c}}$ and $\sigma_{\mathrm{r}}$ along the radius is shown in fig 1., taking radius along $y$-axis and stresses along $x$-axis.

Table 1-Radial Stress or Circumferential Stress by analytical method

\begin{tabular}{|l|l|l|l|l|}
\hline Sr.no. & $\begin{array}{l}\text { Radius } \\
(\mathbf{m})\end{array}$ & $\begin{array}{l}\text { Circumferential } \\
\text { stress }\left(\boldsymbol{\sigma}_{\boldsymbol{c}}\right) \mathbf{N} / \mathbf{m}^{2}\end{array}$ & $\begin{array}{l}\text { Radius } \\
(\mathbf{m})\end{array}$ & $\begin{array}{l}\text { Radial } \\
\text { stress } \\
\left(\boldsymbol{\sigma}_{\boldsymbol{r}}\right) \\
\mathbf{N} / \mathbf{m}^{2}\end{array}$ \\
\hline 1. & 0.0125 & 2.05 & 0.021 & 1.086 \\
\hline 2. & 0.013 & 1.97 & 0.02236 & 3.80 \\
\hline 3. & 0.014 & 1.85 & 0.023 & 1.33 \\
\hline 4. & 0.015 & 1.75 & 0.024 & 1.30 \\
\hline 5. & 0.016 & 1.66 & 0.025 & 1.28 \\
\hline
\end{tabular}

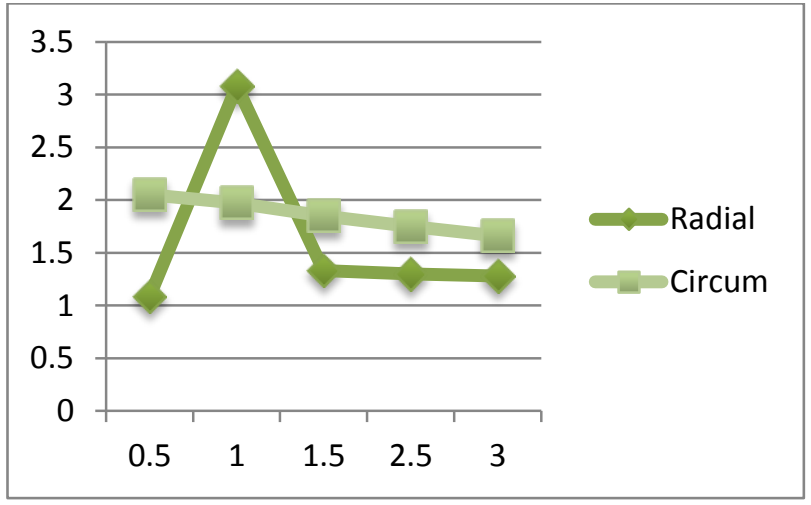

Fig 1.-The variation of $\sigma_{c}$ and $\sigma_{r}$ along the radius is shown in

\section{IV-STRESS ANALYSIS BY FINITE ELEMENT METHOD}

Finite Element Method is the micro mechanical analysis which is now-a-days used as a powerful end an efficient tool for understanding the stress-strain behaviour of the structure. Ansys software package was used to carry stress analysis by FEM. The following results were obtained.
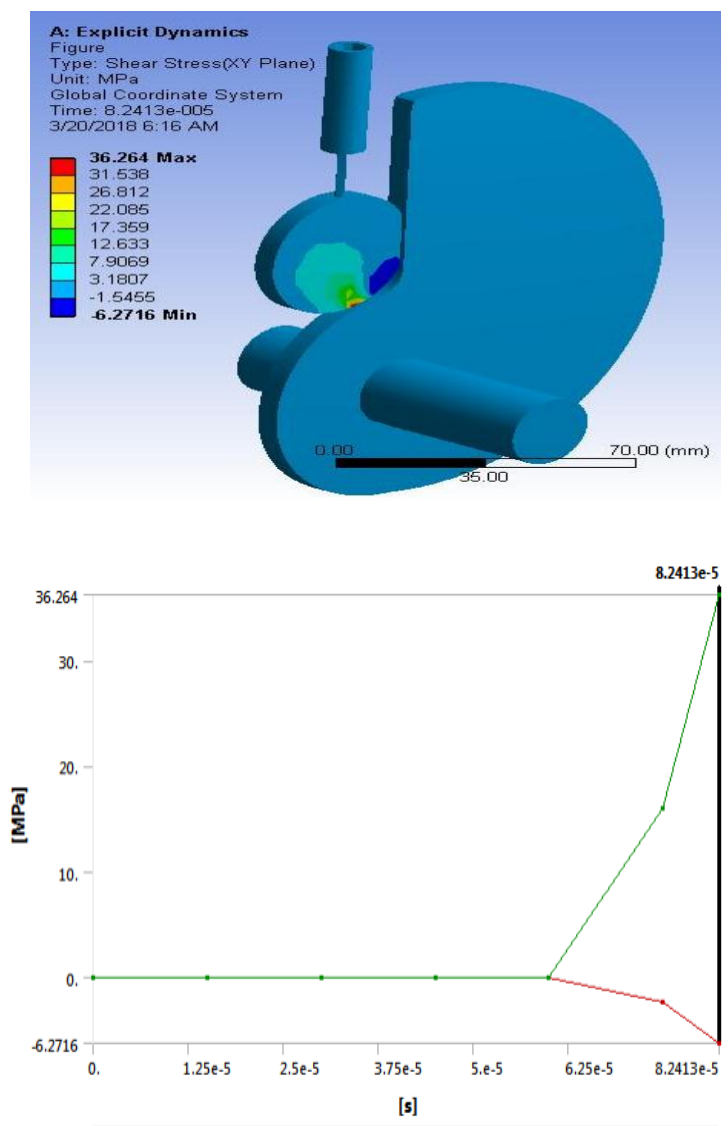

Fig 2- Shear stress on cam 


\section{International Journal of Innovations in Engineering and Science, www.ijies.net}
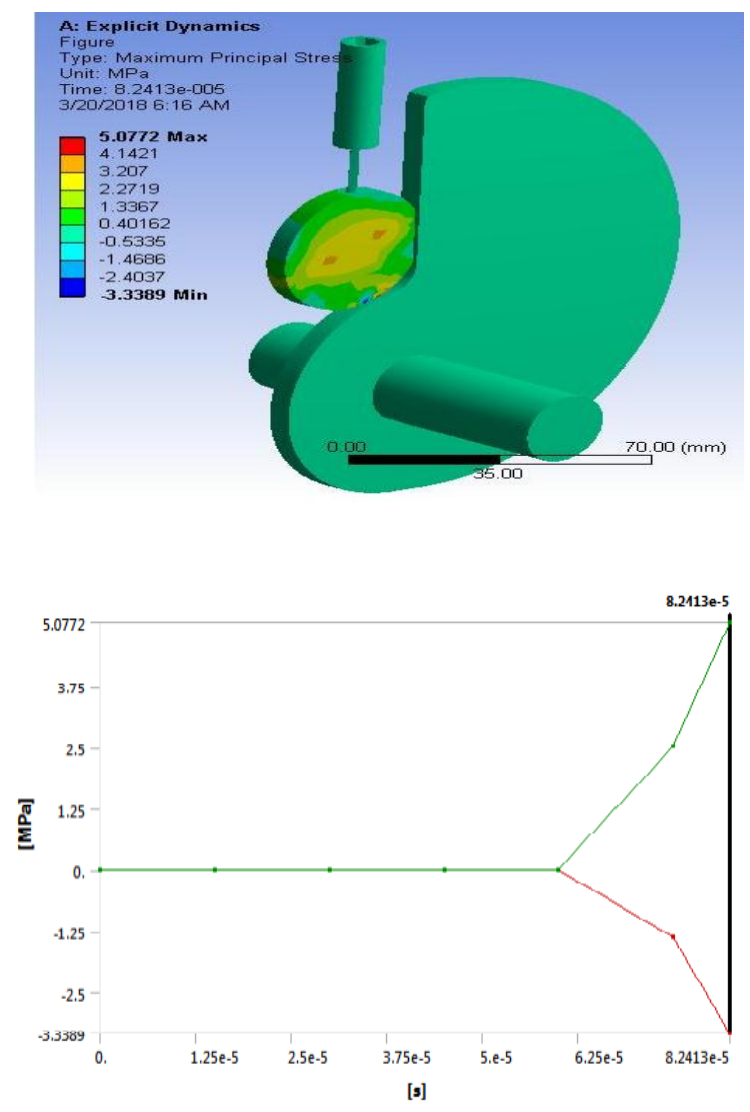

Fig 3.-Maximum principal stress
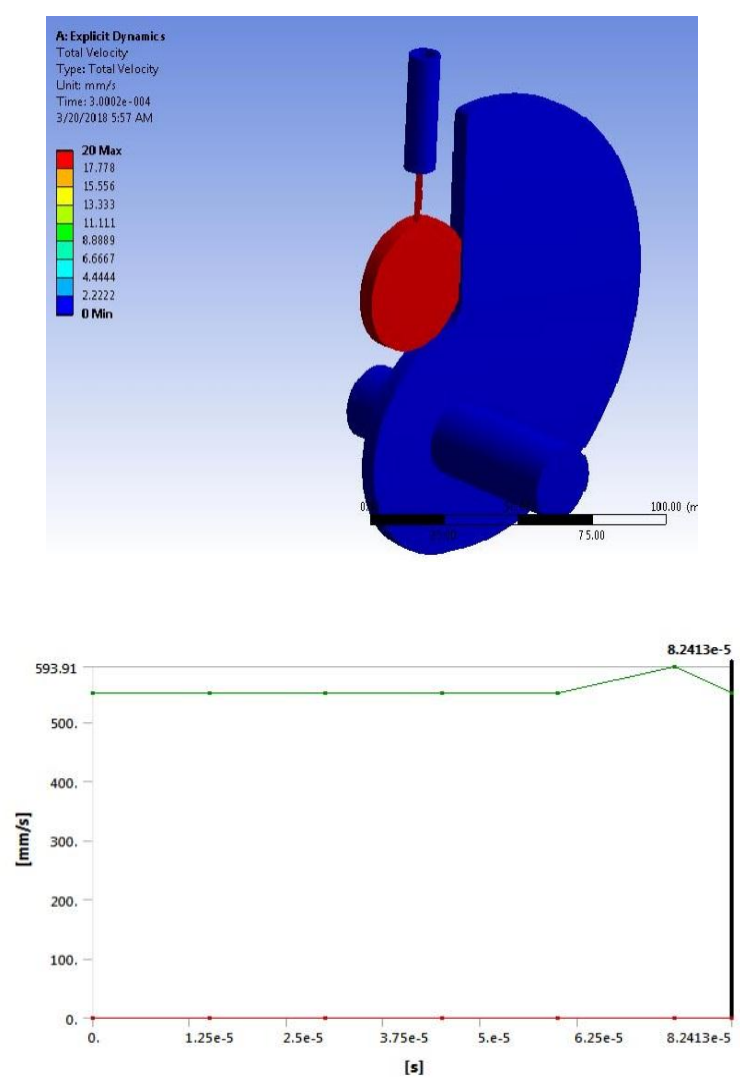

Fig 4-Maximum velocity

\section{V- STRESS ANALYSIS BY PHOTOELASTIC (EXPERIMENTAL) METHOD}

Certain transparent material e.g. plastics are isotropic when unstressed, but becomes doubly refracting when subjected to stress or strain. This phenomenon is called as 'Photo-elastic Effect'. The development of photoelasticity is entirely due to this particular property of Photo elastic materials.

The Cam for the present work was made by casting a photoelastic material. The mould walls of the acrylic sheets are thoroughly cleaned with spirit for degreasing. The spacer is paced in between these walls to make a gap of $6 \mathrm{~mm}$. Then the whole assembly placed in the channel. Before placing this assembly, the steel strips of $1 \mathrm{~mm}$ thick are kept along both the edge of the channel. The strips are used to distribute pressure force towards the walls. The bolts of L-head are tightened with L-key. The same strips of $1 \mathrm{~mm}$ thick are supported along the outer edge boundaries of the walls. The walls are clamped with adequate number of ' $\mathrm{C}$ '- clamps. One side of the mould is kept open for pouring the mixture. Initially the mould is tested for leakage by pouring the water into it. It is kept for one day, and it is found that, there is no leakage from the mould is ready for casting. The set up of the mould is as shown in fig.
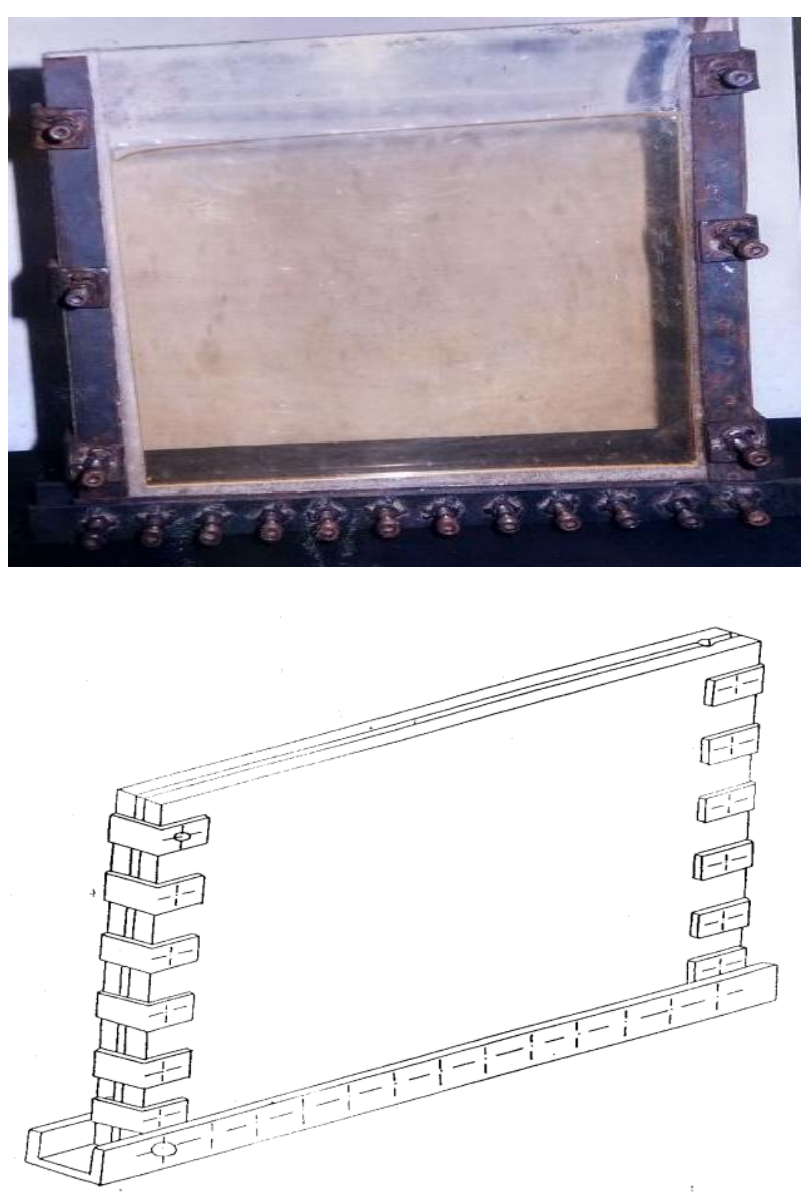

Fig 5-Assembly of Mould 


\section{International Journal of Innovations in Engineering and Science, www.ijies.net}

Araldite CY-230 along with hardener HY-951 is used for casting the sheets. For every $100 \mathrm{cc}$ of araldite 10.5 cc of hardener is mixed. The resin is heated in oven up to $50^{\circ} \mathrm{C}$ to $80^{\circ} \mathrm{C}$ for about one hour to remove all air bubbles and moisture. Then it is cooled down slowly to the room temp. The hardener is added slowly by stirring the mixture continuously. The mixture should be stirred in one direction for ten minutes till it is transparent, clear and homogeneous.

Now, it is ready for pouring in the mould for preparing the sheet, A funnel is used for proper pouring of mixture. The pouring should be completed within ten minutes. Otherwise, the mixture will get settled before pouring into the mould. The reaction between resin and hardener is exothermic.

\section{Casting Procedure:}

The mould is completely filled by the mixture, i.e. up to the top surface. The mould is kept at this position for proper curing at room temperature. For easy removal of the sheet from the mould, the curing time will -be sixteen to eighteen hours is sufficient. After curing time the sheet is removed from the mould carefully. The sheet in this stage is slightly elastic. So it is kept on the perfect flat transparent glass for further curing. The total curing time is about one week. The curing time depends upon the percentage of hardener in the mixture. As percentage of hardener in the mixture increases, the total curing time decreases and vice-versa.

From cured sheet about twenty mm wide portion along all edges is to be discarded, to ensure that the specimen should be free from residual stresses. After discarding the edges remaining portion is specimen. The sheet is to be tested in Polariscope to ensure that the sheet should be free from the residual stresses. The test models prepared from this sheets do not required any surface polishing operation.

\section{VI- PREPARATION OF PHOTOELASTIC MODEL}

\section{Photoelastic Model of A Palte With Cutout}

The drawing of plate is prepared on AUTOCAD to the actual size of plate with circle, triangle and square cut-out. Then the drawing is pasted on the Photoelastic sheet and it is cut by using model cutter, providing 2 to 3 $\mathrm{mm}$ allowance. Finally model is finished to the required size by filing and using fine emery paper. The required holes are drilled in the model for proper mounting in the loading fixture. The model of plate with circle, triangle and square cut-out is used for analysis.

\section{Calibration Disc}

To prepare circular disc of $6.5 \mathrm{~cm}$. diameter, The Photo elastic sheet is cut and fixed between two cylindrical wooden pieces by giving the rubber packing for proper grip. One wooden piece is fixed in the chuck and other is supported by tail stock and dead centre of the lathe. The machining is done at high speed and low feed, with low depth of cut. Coolant is added continuously to avoid the stress locking.

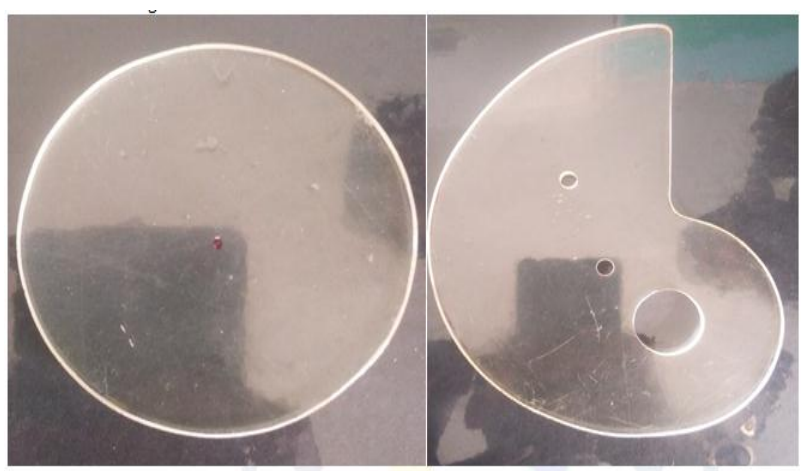

Fig. 6- Exact test model of calibration disc and cam

\section{Determination of Material Fringe Value}

Calibration of Photoelastic sheet is done in order to determine the material fringe value of the material. The disc is loaded on the frame of Polari. The bright field set up used for observing the fringe order developed in the disc as shown in the photograph. The fringe order is developed is directly proportional to compressive load applied on the disc. The centre of the disc is considered for analysis purpose. The lower and higher order fringe is observed for that point.

Tardys Method Of Compensation to Determine Fractional Fringe Order To determine the accurate fringe order, this method is used. First the lower order fringe is passed through point of interest by rotating analyser in clockwise direction and analyser reading is noted down. The actual fringe order is calculated by adding analyser reading to lower order fringe. Then higher order fringe is passed through point of interest by rotating analyser in anticlockwise direction and analyzer reading is noted down. The actual fringe order is determine by subtracting analyses reading from higher order fringe. The average of both the readings is taken to determine actual fringe order for calculation of material fringe value. 


\section{International Journal of Innovations in Engineering and Science, www.ijies.net}

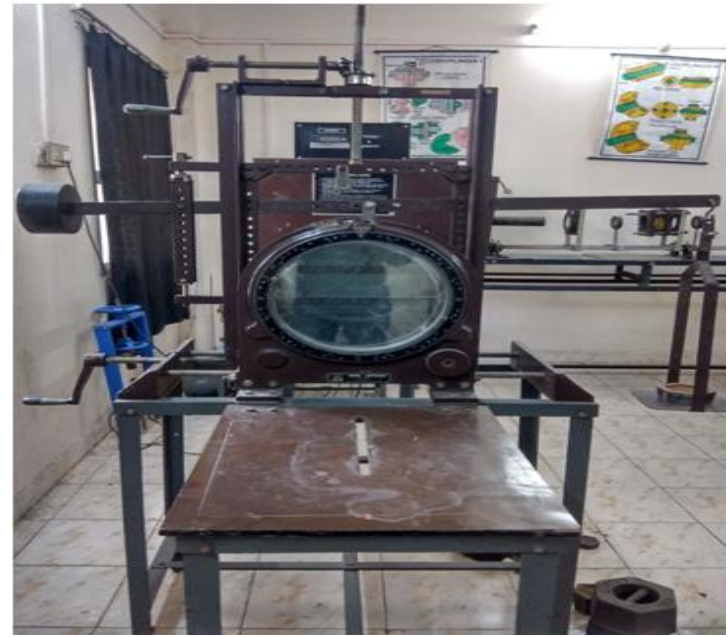

Fig. 7-Polariscope

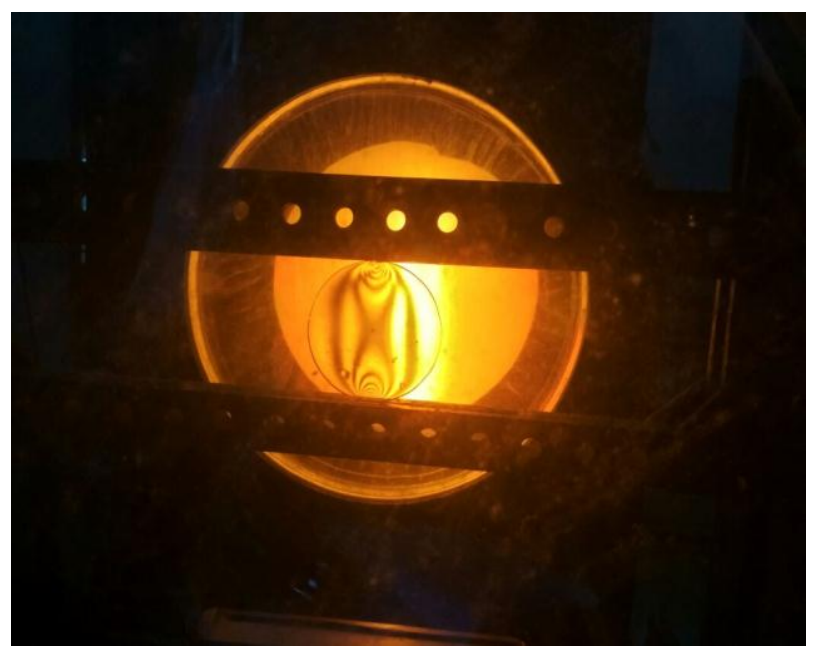

Fig 8-. Fringes developed in calibration disc, loaded under diametric compression

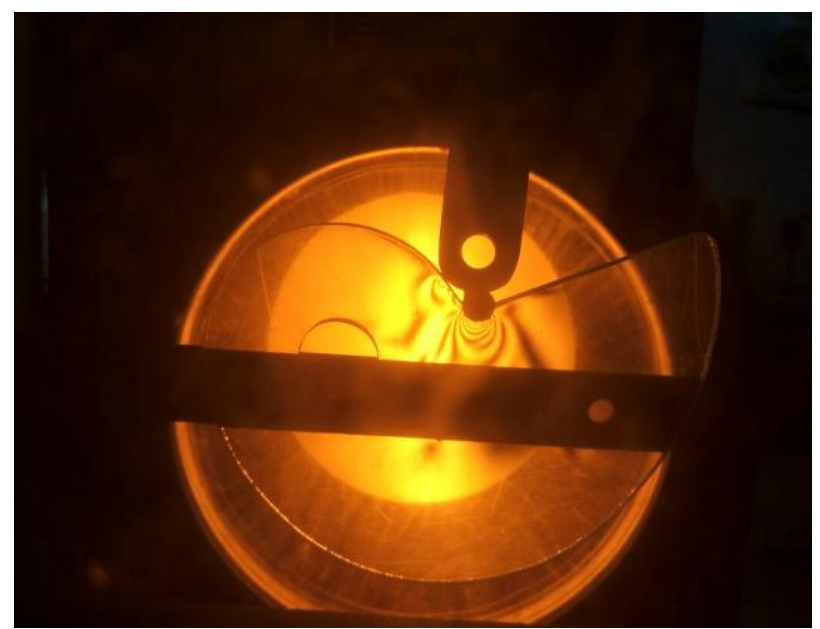

Fig 9-Fringes developed in cam

\section{VII-CALCULATION FOR THE CALIBRATION OF THE DISC}

i) Diameter of disc (D) $=6.5 \mathrm{~cm}$

ii) Weight in the pan (W) $=10 \mathrm{Kgf}$

iii) Actual load coming on the disc $(\mathrm{P})=\mathrm{W} \times$ Lever Ratio

$$
\begin{aligned}
& =10 \times 3.03 \\
& =30.3 \mathrm{Kgf}
\end{aligned}
$$

iv) Material fringe value $\left(F_{\sigma}\right)=\frac{8 \times P}{\pi D N}$

$$
\begin{aligned}
& =\frac{8 \times 10 \times 3.03}{\pi \times 6.5 \times 1.090} \\
& =10.89 \mathrm{Kgf} / \mathrm{cm} \\
& =10.89 \mathrm{~N} / \mathrm{mm}
\end{aligned}
$$

\section{Calculations for Experimental Stress}

Experimental Stress, $\sigma=\frac{N F_{\sigma}}{h}$

Where,

$\sigma$ - Experimental stress

$\mathrm{N}$ - Fringe order

$\mathrm{F}_{\sigma^{-}}$- Material fringe value

$\mathrm{h}-$ Thickness of model

$$
\begin{aligned}
\therefore \sigma= & \frac{N F_{\sigma}}{h} \\
= & \frac{71.26 \times 10.52}{6} \\
& \therefore \sigma=124.94 \mathrm{~N} / \mathrm{mm}^{2}
\end{aligned}
$$

\section{VIII-CONCLUSION}

The stress analysis is carried out on a snail cam by analytical, FEM and photoelastic (experimental) techniques and results are put in the comparative manner. It is observed that the maximum stress in cam occur at downward stroke of follower where follower strikes on cam with return stroke. From finite element analysis, the following findings are reported. Depending on the load, effects on stress concentration varies. However, in general as load increases, fringes also increases. By finite element method, we found maximum stress of $130 \mathrm{Mpa}$ for rotation of cam about $45 \mathrm{rpm}$. From experimental analysis of cam with different load conditions, due to point load on cam where follower strikes, maximum fringes occurred. This point shows the area where cam may damage. So it is preferable to use maximum thickness of cam where maximum fringes generated. In experimental analysis, maximum stress occurred is $125 \mathrm{MPa}$ for $54 \mathrm{~N}$. 
Vol. 6, No. 1, 2021, PP. 32-37

International Journal of Innovations in Engineering and Science, www.ijies.net

\section{REFERENCES}

[1] Pástor, M., Hagara M., \& Kostka J., 2015. Stress Analysis Performed by Photoelasticity and Digital Image Correlation. Applied Mechanics and Materials. 816. 474-481.

[2] Driscoll H., Koerger H., Senior T., Haake S. 2010, The use of photoelasticity to identify surface shear stresses during running, Procedia Engineering 15. 3047-3052.

[3] Hawong J. S., Jeong N., Kyo-Hyoung K., O-sung K., Gun K., Park S., 2010, A study on the development of photoelastic experimental hybrid method for colour isochromatics, Journal of Mechanical Science and Technology. 24. 1279-1287.

[4] Dinesh L., Prasanth K. M., 2016, Study on Stress Analysis of Araldite HY-951 and CY-230 Bell Crank Lever using Photoelasticity and FEM, Journal of Information Engineering and Applications 6: 10-22.

[5] Tesfie N., 2014, Finite Element Based Surface Wear Analysis of Cam and Follower System, Addis Ababa University Institute of Technology. 